\title{
Revisiting oceanic elves and lightning occurrence rate during EI Niño and La Niña episodes over a 10-year time frame
}

\author{
Yen-Jung $\mathrm{Wu}^{1,{ }^{*}}$, Rue-Ron $\mathrm{Hsu}^{1}$, Alfred Bing-Chi Chen ${ }^{2}$, Han-Tzong Su${ }^{1}$, Shu-Chun Chang ${ }^{1}$, \\ Jung-Kuang Chou ${ }^{1}$, Yi-Jen Lee ${ }^{1}$, and Kang-Ming Peng ${ }^{1}$ \\ ${ }^{1}$ Department of Physics, National Cheng Kung University, Tainan City, Taiwan \\ ${ }^{2}$ Institute of Space and Plasma Sciences, National Cheng Kung University, Tainan City, Taiwan
}

\section{Article history:}

Received 29 February 2016

Revised 1 June 2016

Accepted 28 July 2016

Keywords:

Elves, Lightning, El Niño Southern Oscillation, Sea surface temperature, Indian-Pacific Ocean interaction, Convection available potential energy (CAPE)

\section{Citation:}

Wu, Y.-J., R.-R. Hsu, A. B.-C. Chen, H.-T. Su, S.-C. Chang, J.-K. Chou, Y.-J. Lee, and K.-M. Peng, 2017: Revisiting oceanic elves and lightning occurrence rate during El Niño and La Niña episodes over a 10-year time frame. Terr. Atmos. Ocean. Sci., 28, 571-581, doi: $10.3319 /$ TAO.2016.07.28.01

\begin{abstract}
The Sprite and Upper Atmospheric Lightning Imager (ISUAL) on board the Taiwanese satellite Formosat-2 accomplished its first decade operating in orbit. A comprehensive method defining the standardized elve anomaly occurrence rate using limb-viewed observation is demonstrated. We revisit the occurrence of elves during El Niño and La Niña and extend the time series analysis to November 2015. The variation in the enhanced elve anomalies occurrence density (AEOD) follows the change in sea surface temperature anomaly (SSTA) in the SSTA-Horseshoe, SSTA-Pacific, and SSTA-Indian Ocean during the warm and cold phases. However, the variation in lightning flash density anomalies (ALFD) is rather ambiguous. The Southern Oscillation Index (SOI) correlation with the Elve Anomaly Index (EAI) remains significant in Tahiti, while the best correlation between SOI and elves is found in the western/central Pacific Ocean with a correlation coefficient as high as 0.7. In the Indian Ocean the 10-year time frame correlation is moderate, but the relation is obvious during the transition phase between a strong El Niño following La Niña in the region where the synoptic circulation is affected. The weaker convection available potential energy (CAPE) in the upwelling synoptic circulation region provides an environment conducive to the development of elve-producing thunderstorms. This work substantiates the relation between elves/lightning and ENSO in a longer10-year time frame in which elves are more sensitive than lightning to ENSO and the variation in the synoptic circulation.
\end{abstract}

\section{INTRODUCTION}

Transient luminous events (TLEs) have been recognized since the 1990s. TLEs are lightning-related optical phenomena in the altitude range from the cloud top to the base of the ionosphere (Franz et al. 1990; Sentman and Wescott 1993; Lyons 1994; Fukunishi et al. 1996 ; Su et al. 2003; Pasko et al. 2010). Since the occurrence of TLEs is usually accompanied by lightning and thunderclouds, TLEs related research has become increasingly prevalent, from small scale cloud microphysics to the global scale study of severe weather. The Sprite and Upper Atmospheric Lightning Imager (ISUAL) on board the Taiwanese FORMOSAT-2 (FS-2) satellite, launched in May 2004, represents the first instrument to make long-term continuous ob-

\footnotetext{
* Corresponding author

E-mail:annephyphy@gmail.com
}

servations of global TLEs from space (Chern et al. 2003). This satellite mission completed an 11-year solar cycle observation in 2015 in reliable condition (Chen et al. 2012) and remains in operation today. Taking advantage of this global survey, Chen et al. (2008) reported on the global distribution of four major types of TLEs (elves, sprites, halos, and gigantic jets). This global analysis included the first recognition that elves are the dominate type of TLE, making up over $80 \%$ of all events. Most elves are missed in ground campaigns because of their short luminous duration, but the space-borne observation avoids the atmospheric attenuation so that emissions in the optical band (Kuo et al. 2007) and in the far ultraviolet region can be recorded by ISUAL (Chang et al. 2010, 2014).

The occurrence of elves is linked with cloud-to-ground lightning with large peak current, generally exceeding 
$60 \mathrm{kA}$ (Barrington-Leigh et al. 2001), in contrast with the median peak currents of ground flashes for two polarities ( -15 and $19 \mathrm{kA}$ ) detected by NLDN (Nag et al. 2014). The electromagnetic pulse generated by these superlative lightning flashes interacts with the base of the ionosphere where the electron density increases abruptly with height (Friedrich and Torkar 1992; Wu et al. 2017), accelerating free electrons which collide with the ambient atoms and molecules to create the optical emission (Inan et al. 1996; Mende et al. 2005; Kuo et al. 2007; Marshall et al. 2010). The recent direct comparison of elves recorded by ISUAL and lightning data from the World Wide Lightning Location Network (WWLLN) (Chen et al. 2014) has shown that the median energy for elve-related lightning is $\sim 1.5 \times 10^{4}$ $\mathrm{J}$, whereas the median energy of the WWLLN lightning strokes is $\sim 9 \times 10^{2} \mathrm{~J}$ (Chen et al. 2014).

With elves as a proxy for lightning with large peak current, the synoptic variation of elves is of interest. Lee et al. (2010) focused in detail on the seasonal variation showing that the active TLE zone migrates seasonally with the Intertropical Convergence Zone (ITCZ) and the South Pacific Convergence Zone (SPCZ) at low latitude, while at higher latitude the active zone lies in the winter storm track. The TLE association with the synoptic deep tropical convection again brings the El Niño Southern Oscillation (ENSO) to center stage.

The El Niño Southern Oscillation (ENSO) is the interannual longitudinal variation in sea surface temperature (SST) and air pressure in the Pacific region (e.g., Walker 1923; Wyrtki 1975), and exerts great influence on the weather and climate worldwide through teleconnection patterns (e.g., Wang et al. 2000; Camberlin et al. 2001; Alexander et al. 2002). The lightning activity on the ENSO time scale has been discussed in several studies (Williams 1992, 2012; Williams 2005; Price 2009; Sátori et al. 2009; Dowdy 2016). Sátori et al. (2009) demonstrated that the lightning occurrence is more frequent during the cold phase (La Niña) than during the warm phase (El Niño) for the Pacific and other oceanic regions. Additional regions were studied in Chronis et al. (2008), demonstrating an enhancement in lightning occurrence during the warm (El Niño) phase in the central Pacific and in the eastern Indian Ocean, while for the southwestern Pacific Ocean and the coasts of Brazil/South Africa the enhancement occurred during the cold (La Niña) phase. More recently, Dowdy (2016) examined seven different modes of variability and found that ENSO is the most influential of all on lightning on the seasonal time scale. These results illustrate that the relation between the lightning occurrence and the ENSO phenomenon is both local and global. The linkage with the exceptional lightning with high peak current highlights the elve activity on the ENSO time scale (Wu et al. 2012).

Wu et al. (2012) studied ISUAL data from 2005 - 2010 and reported that the anomaly in elve occurrence rate is strongly linked to the sea surface temperature during both ENSO phases, in the spatial patterns and also in time series. A significant change in the elve occurrence rate is identified in the Central Pacific warm pool and in the ENSO horseshoe pattern, both featured regions for ENSO study (Wang et al. 2016), as well as in Tahiti in the South Pacific Ocean which varies anti-phase with the Pacific warm pool region. Given that the El Niño in 2015 - 2016 has been recognized as a strong ENSO event, it is timely to extend the data analysis to the end of 2015 and revisit the issue.

We apply the analysis used in Wu et al. (2012) in this study to examine the variations of elves and lightning in the 10-year time frame including the historical El Niño in 2015. With the aim to clarify the impact of the ENSO events on the mesospheric elves occurring near the lower ionosphere boundary, the LIS-TRMM lightning data (Christian et al. 1999, 2003), the NOAA Optimum Interpolation Sea Surface Temperature (Reynolds et al. 2002), the Niño 3.4 index and the Southern Oscillation Index (SOI) are all inter-compared. The observational data and the instruments for this study are described in section 2. A detailed description of the analysis methods is given in section 3 . The variations of elves and lighting occurrences and the quantitative correlation analysis during ENSO episodes in the Pacific Ocean are revisited in section 4. The areas in the Indian Ocean are discussed in section 5. More discussion about the physical mechanism is addressed in section 6 . The last section provides the conclusion.

\section{INSTRUMENTS AND DATA}

The elve data from ISUAL-FS-2 and the lightning data from the Lightning Imaging Sensor (LIS) on board the Tropical Rainfall Measuring Mission (TRMM) are intercompared in this study. The details of the satellite missions and data format are described below:

FORMOSAT-2 is a Sun synchronous satellite with an orbital altitude of $891 \mathrm{~km}$. The ISUAL nighttime payload provides observations of TLEs, airglow and aurora in global limb-view at the fixed local time of $11 \mathrm{pm}$. ISUAL is composed of three instruments which serve different aspects: the Imager with intensified CCD, the Spectrophotometer (SP) and the Array Photometer (AP) (Chern et al. 2003). So long as a flash is detected by the trigger detection hardware driven by either SP channel 1 (150 - $290 \mathrm{~nm})$, the SP channel 2 (centered at $337 \mathrm{~nm}$; bandwidth $5.6 \mathrm{~nm}$ ) or the SP channel $6(228.2-410.2 \mathrm{~nm})$, the data capture mode is initiated and a preprogrammed sequence of data is recorded in the storage device. Elves are identified manually with the Imager according to their morphology (Kuo et al. 2007) along with the apparent vertical motion shown in the AP. Elves are documented both in front of and behind the Earth's limb (Kuo et al. 2007).

The pros and cons of limb-viewed observations are 
worthy of discussion. Limb-viewing is essential for observing the vertical propagation and shape of TLEs, but the larger error in the event's geographical location in comparison with the nadir-viewed mission is inevitable because of the uncertainty caused by the projection. Before considering the spatial projection of each event, a global map is gridded with $0.5^{\circ} \times 0.5^{\circ}$ resolution, and then a probability weighting function as a form of 2D Gaussian distribution in a 13 grid by 13 grid area with the maximum probability $50 \%$ at the center is applied. Thus, the occurrence probability of an event in each grid $P_{e, g 1, g 2}$ is defined

$P_{e, g 1, g 2}=W_{e, g 1, g 2} /$ Area $_{g 1, g 2}$ in grid $(g 1, g 2)\left(\# \mathrm{~km}^{-2}\right)$

$W_{e, g 1, g 2}=$ the probability weighting function of an event in grid $(g 1, g 2)$

Area $_{g 1, g 2}=$ the grid area $(g 1, g 2)$

The seasonal occurrence probability is the sum of all $P_{e, g 1, g 2}$ in season $i$

$P_{i, g 1, g 2}=\sum_{a l l} P_{e, g 1, g 2}$ in grid $(g 1, g 2)\left(\# \mathrm{~km}^{-2}\right)$

Two quantities pertaining to elve occurrence discussed in the present work are then defined below:

(1) The elve occurrence density (EOD) in each grid in season $i\left(\# \min ^{-1} \mathrm{~km}^{-2}\right)=P_{i, g 1, g_{2}} /$ observing time in each $\operatorname{grid}(\mathrm{min})$

(2) The elve occurrence rate (EOR) comes from the occurrence density multiplied by the area per grid: Occurrence rate in each $\operatorname{grid}\left(\# \mathrm{~min}^{-1}\right)=P_{i, g 1, g 2} \times$ Area $_{g 1, g 2} /$ observing time in each grid.

Chen et al. (2008) showed the global distribution of TLEs for the first time. The results were surprising as the occurrence rates for sprites and halos are less than that for elves, while no previous publications discussed the occurrence rate of elves. From July 2004 to November 2015, ISUAL has recorded 24984 elves in 32622 identifiable TLE events over the world which amounts to $76 \%$ of the total population. In the global distribution of elves shown in Fig. 1, these TLEs are concentrated over the areas previously considered in Chen et al. (2008) which are the Caribbean Sea, the South China Sea, the east Indian Ocean, the central Pacific Ocean, the west Atlantic Ocean, and the southwest Pacific Ocean. In addition to the areas listed above, an active zone for elves is found in the fourth "chimney" of global lightning activity (Williams 2013; Ortega et al. 2014) over Tahiti in the southern Pacific Ocean. Further discussion of the elves and lightning over Tahiti will be presented in section 4 as this area shows a strong variation on the ENSO time scale (Wu et al. 2012).

The Tropical Rainfall Measuring Mission (TRMM) launched in November 1998, with the mission terminated by the satellite's re-entry to Earth in June 2015 is widely recognized as a major success in the scientific community. TRMM continuously provided rainfall parameters and lightning flash measurements in a $\pm 35^{\circ}$ latitude region and over the oceans where the procurement of meteorological data on a daily bases is difficult. The LIS records the time and location of lightning occurrence and the radiant energy during both daytime and nighttime with a narrow band-filtered (centered at $777.4 \mathrm{~nm}$ ) optical sensor directed in the nadir direction.(Christian et al. 1999; Boccippio et al. 2000). The flash rate and flash density are derived following the definition of the EOD and EOR:

(1) The lightning flash density (LFD) $\left(\# \mathrm{~min}^{-1} \mathrm{~km}^{-2}\right)=$ flash count in each grid (counts) / observing time in each grid $(\mathrm{min}) /$ area in each grid $\left(\mathrm{km}^{2}\right)$.

(2) The lightning flash rate (LFR) $\left(\# \min ^{-2}\right)=$ flash count in each grid (counts) / observing time in each grid.

Version 2 of the NOAA Optimum Interpolation (OI)

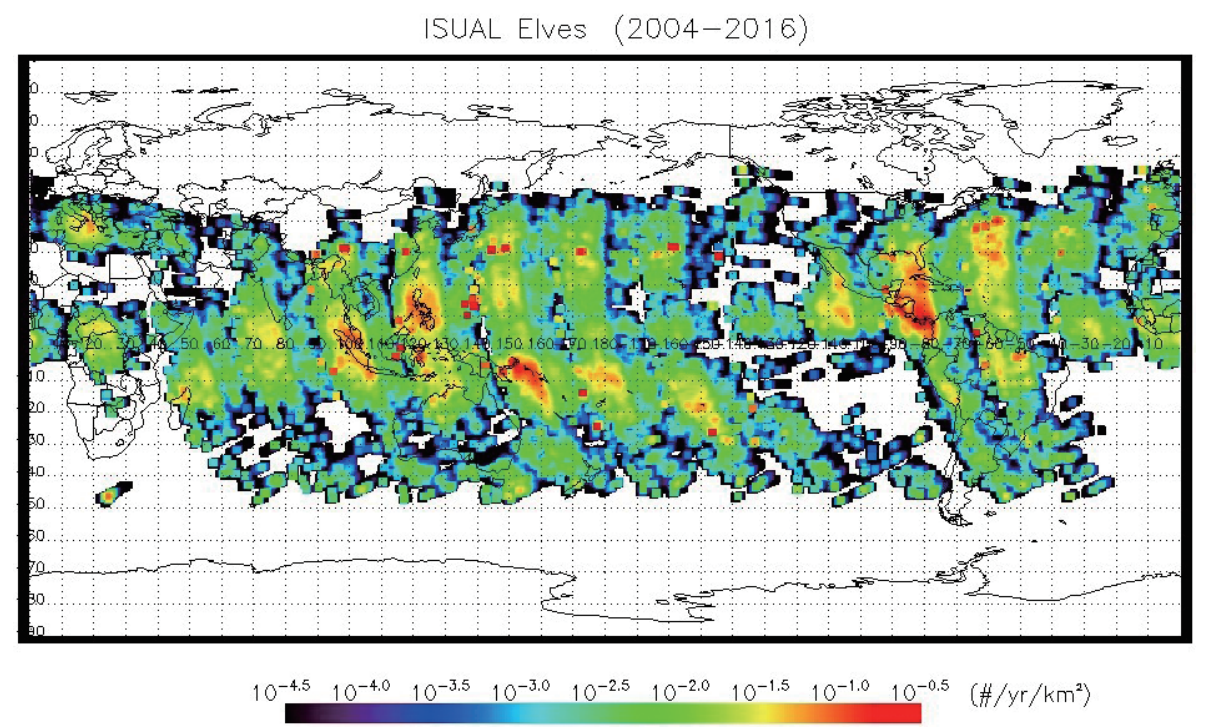

Fig. 1. Global distribution of elve occurrence density (EOD). Note that the occurrence density is lower in the observing gap due to the orbital restriction. The cumulative observation time of ISUAL is demonstrated in Chen et al. (2008). (Color online only) 
Sea Surface Temperature (Reynolds et al. 2002) is applied to compare with the elve occurrence rate and lightning flash rate. All of the gridded data discussed in this study was processed with a $2.5^{\circ} \times 2.5^{\circ}$ running mean and binned in a $0.5^{\circ}$ $\times 0.5^{\circ}$ grid. The exact time frame for this analysis is June 2005 to November 2015 with monthly data converted into seasonal data using the common convention of 3-month blocks: DJF, MAM, JJA, and SON.

\section{ANALYSIS METHODS}

The Niño 3.4 Index is the standard quantity used to identify the sea surface temperature anomaly (SSTA) in the region bounded by $120-170^{\circ} \mathrm{W}$ and $5^{\circ} \mathrm{S}-5^{\circ} \mathrm{N}$ (Trenberth et al. 1997). When the Niño 3.4 Index is greater (less) than or equal to $+0.5(-0.5)$, a warm (cold) event is identified. As shown in Fig. 2, the data scope includes 42 three-month seasons, where eight seasons are considered in the warm phase and eleven in the cold phase. Following the method in Wu et al. (2012), the standardized Anomaly in Elve Occurrence Density (AEOD) and Anomaly in Lightning Flash Density (ALFD) during the warm phase and cold phase are defined as below:

$$
\begin{aligned}
& A E O D_{\text {warm (cold) }}=Z_{\text {warm (cold) }}^{\text {elve }}= \\
& \frac{\frac{1}{n_{\text {cold (warm) }}} \sum_{i}^{\text {cold (warm) }} E O D_{i}^{\prime}-\mu_{\text {elve }}^{\prime}}{\sigma_{\text {elve }}^{\prime} / \sqrt{n}}
\end{aligned}
$$

$E O D^{\prime}=$ Seasonal-variation-removed EOD

$\mu_{\text {elve }}^{\prime}=$ Mean of the long term $E O D^{\prime}$

$\sigma_{\text {elve }}^{\prime}=$ The standard deviation of the long term $E O D^{\prime}$

$n=42$ seasons from JJA of 2005 to SON of 2015

$Z_{\text {warm (cold) }}^{\text {elve }}=$ The notation in Wu et al. (2012)

$$
\begin{aligned}
& A L F D_{\text {warm (cold) }}=Z_{\text {warm (cold) }}^{\text {lightning }}= \\
& \frac{\frac{1}{n_{\text {cold (warm) }}} \sum_{i}^{\text {cold (warm) }} L F D_{i}^{\prime}-\mu_{\text {lightning }}^{\prime}}{\sigma_{\text {lightning }}^{\prime} / \sqrt{n}}
\end{aligned}
$$

$L F D^{\prime}=$ Seasonal-variation-removed LFD

$\mu_{\text {lightning }}^{\prime}=$ Mean of the long-term $L F D^{\prime}$

$\sigma_{\text {lightning }}^{\prime}=$ The standard deviation of the long term $L F D^{\prime}$

$Z_{\text {warm (cold) }}^{\text {lighting }}=$ The notation in Wu et al. (2012)

Aiming to reveal the areas where the changes in AEOD and ALFD are statistically significant, the confidence interval is considered as the quantitative criterion. Since the mean and standard deviation of the population are unknown, the Student-t distribution is applied as the null distribution to test the statistics in terms of the Central Limited Theorem (Westfall and Henning 2013). The critical value of the sample number $\mathrm{n}=42$ for a $90 \%$ confidence interval is 1.684 in the Student-t distribution. This means that AEOD and ALFD increase (decrease) significantly when they are higher (lower) than $1.684(-1.684)$.

In addition to the Niño 3.4 Index, the SOI is another commonly used ENSO index historically, and is based on the observed difference of sea level pressure between Tahiti and Darwin, Australia as a measure of the large scale fluctuations in ENSO. This measurement is anti-phase with the Niño 3.4 index, with negative values for the warm phase and positive values for the cold phase. Similarly, the Elve Anomaly Index (EAI) and the Lightning Anomaly Index (LAI) for season $i$ are defined in order to find the pair of areas where the lightning and elve activity vary in phase and anti-phase with ENSO:

$$
\begin{aligned}
& \mathrm{EAI}_{\mathrm{i}} \equiv \frac{E O R_{1, i}-\mu_{\text {elve_1 }}}{\sigma_{\text {elve_ } 1} / \sqrt{n}}-\frac{E O R_{2, i}-\mu_{\text {elve_ } 2}}{\sigma_{\text {elve_2 }} / \sqrt{n}} \\
& \mathrm{LAI}_{\mathrm{i}} \equiv \frac{L F R_{1, i}-\mu_{\text {lightning_1 } 1}}{\sigma_{\text {lightning_1 }} / \sqrt{n}}-\frac{L F R_{2, i}-\mu_{\text {lightning_2 }}}{\sigma_{\text {lightning_2 }} / \sqrt{n}} \\
& \mu_{\text {elve (lightning } \_1,2}=\frac{1}{n} \sum_{i}^{1,2} E O R(L F R) \\
& \sigma_{\text {elve (lightring) }}=\text { The standard deviation of EOR (LFR) }
\end{aligned}
$$

where 1 and 2 are for two different areas. $\mathrm{EAI}_{\mathrm{i}}$ and $\mathrm{LAI}_{\mathrm{i}}$ are the replaced indices for , respectively, in Wu et al. (2012). The equations are the same but with the flexibility in changing areas.

Detailed application of the indices described in section 3 is given in sections 4 and 5. The regions examined in this study are marked in Fig. 3, including 3 shaded areas characterized by significant SSTA and the block areas used in EAI and LAI analysis in the Pacific region.

\section{REVISITING THE OCCURRENCE RATES OF ELVES AND LIGHTNING DURING ENSO PHASES WITH THE EXTENDED DATA THROUGH DECEMBER 2015.}

The significant SST-sensitive regions of elves and lightning on the ENSO time scale from 2005 to 2010 were discussed by Wu et al. (2012). It was found that elve and lightning occurrence densities vary in phase with SST in the central Pacific and the western Pacific regions. Additionally, both the elve and lightning occurrences were found to vary out of phase with the SST in ENSO episodes in the Tahiti region, where the response to ENSO is strong but anti-phase to SSTA. This could be due to the southeastward shift in the SPCZ during La Niña (Haffke and Magnusdottir 2013). Additional discussion pertaining to lightning and elve activity in the ITCZ and SPCZ is addressed in section 6.

The AEOD and ALFD in the ENSO phases are presented in Fig. 4, with red and blue colors denoting areas with statistically significant positive and negative change (respectively) over the $90 \%$ confidence interval, whereas the grey color marks the area without statistically significant change. It is apparent that AEOD and ALFD in both the warm and cold phase reflect the SSTA pattern, which resembles that of the recently documented El Niño Modoki or the central Pacific El Niño (Ashok et al. 2007; Yeh et al. 2009). However, the thick SSTA contour over the $90 \%$ confidence interval 


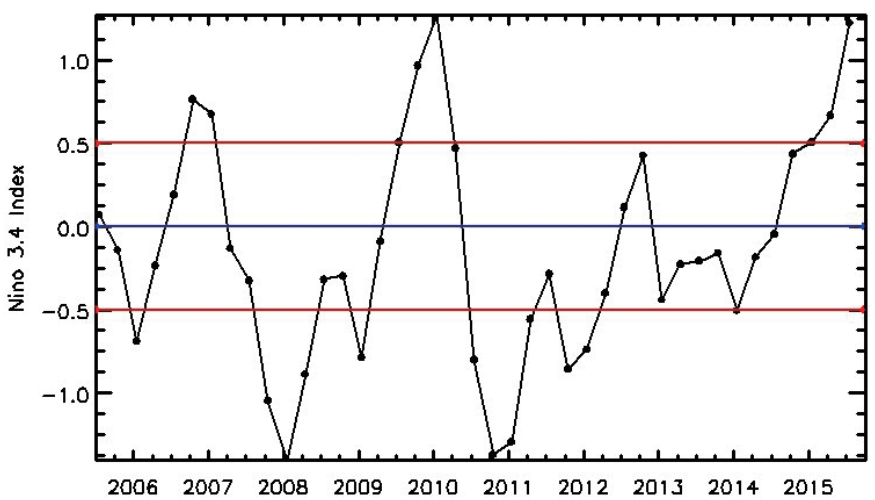

Fig. 2. The Niño 3.4 index with seasonal resolution (DJF, MAM, JJA, SON) from JJA 2005 to SON 2015. (Color online only)

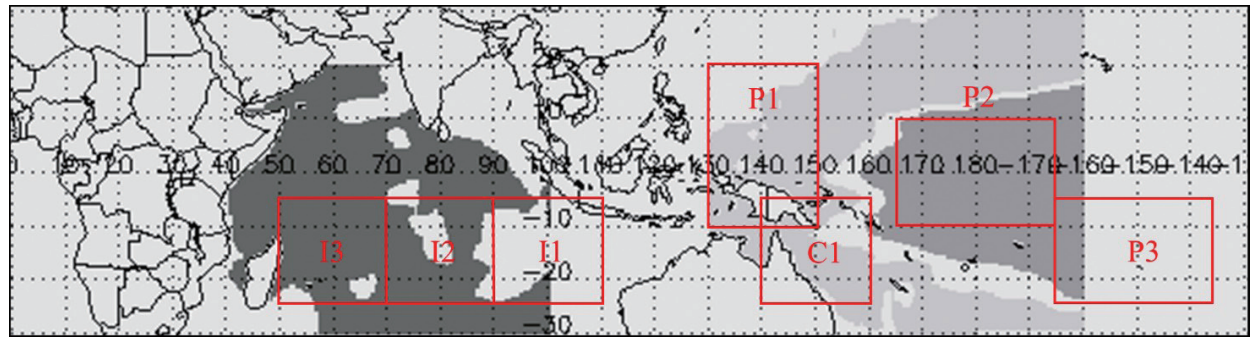

Fig. 3. The areas for elves and lightning analyzed in this study are identified with red rectangles (see also in Table 2). The shaded areas from left to right are SSTA-Indian Ocean, SSTA-Horseshoe, and SSTA-Pacific discussed in sections 5 and 6. (Color online only)
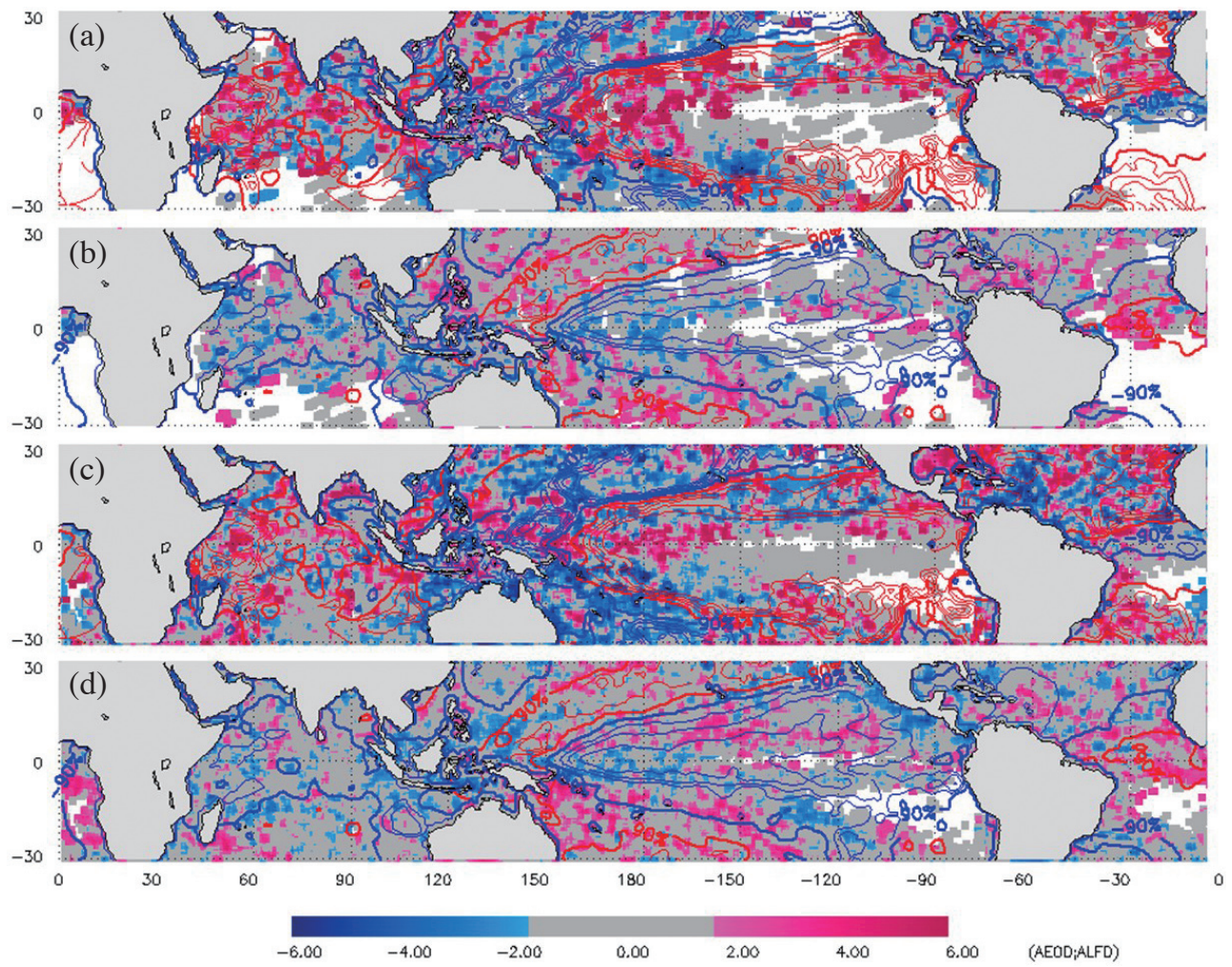

Fig. 4. The AEOD (top two panels) and ALFD (bottom two panels) during ENSO for the warm phase [(a) and (c)] and the cold phase [(b) and (d)]. Color codes: red shaded, area with significant occurrence increase over 90 percentile confidence interval; blue shaded, area with significant occurrence decrease over 90 percentile confidence interval; gray shaded area with no statistically significant changes. The red (blue) thick isopleths indicate where SSTA enhancement (reduction) reaches $90 \%$ confidence interval. (Color online only) 
matches better with AEOD changes also over the $90 \%$ confidence interval. To understand how much area has prominent SSTA change, the percentage of the area with enhanced or reduced AEOD and ALFD is listed in Table 1. Two analyzed regions, SSTA-Horseshoe and SSTA-Pacific, are defined by SSTA over $90 \%$ and less than $-90 \%$ confidence intervals in the warm phase, respectively (Fig. 3). A larger fractional area $(32.9 \%)$ in SSTA-Pacific is found to have significant AEOD increasing in the warm phase while the AFLD is suppressed (24.4\%). For SSTA-Horseshoe, the AEOD enhance- ment in the cold phase is more remarkable (20\%) than in the reduced region $(5.5 \%)$. In other words, the variation in AEOD follows the change in SSTA in the SSTA-Horseshoe and SSTA-Pacific regions, whereas the variation in ALFR does not. This result implies that elves are more responsive than lightning to ENSO over the Pacific Ocean, consistent with the results in Wu et al. (2012).

Three pairs of areas showing statistically significant correlations between EAI/LAI and SOI (Fig. 5) are: Pair (1) central Pacific - Tahiti, Pair (2) west Pacific - central Pacific,

Table 1. The areas showing a significant enhancement or suppression of elve/lightning occurrence during two phases of ENSO. Bold print indicates areas with a more significant enhancement or suppression of AEOD and ALFD during ENSO.The regions are marked in Fig. 3.

\begin{tabular}{c|c|cc|cc}
\hline \multirow{2}{*}{ Region } & \multirow{2}{*}{ Event } & \multicolumn{2}{|c|}{ Warm Phase } & \multicolumn{2}{c}{ Cold Phase } \\
\cline { 3 - 6 } & & Enhance Area & Reduce Area & Enhance Area & Reduce Area \\
\hline \multirow{2}{*}{ SSTA-Pacific } & Elve & $32.9 \%$ & $13.9 \%$ & $10.9 \%$ & $11.4 \%$ \\
& Lightning & $16.9 \%$ & $24.4 \%$ & $24.0 \%$ & $8.1 \%$ \\
\hline \multirow{2}{*}{ SSTA-Horseshoe } & Elve & $20.8 \%$ & $20.2 \%$ & $20.0 \%$ & $5.5 \%$ \\
& Lightning & $20.6 \%$ & $35.7 \%$ & $17.6 \%$ & $10 \%$ \\
\hline \multirow{2}{*}{ SSTA-Indian Ocean } & Elve & $22.9 \%$ & $11.8 \%$ & $9.6 \%$ & $13.9 \%$ \\
& Lightning & $18.0 \%$ & $14.7 \%$ & $6.1 \%$ & $9.8 \%$ \\
\hline
\end{tabular}
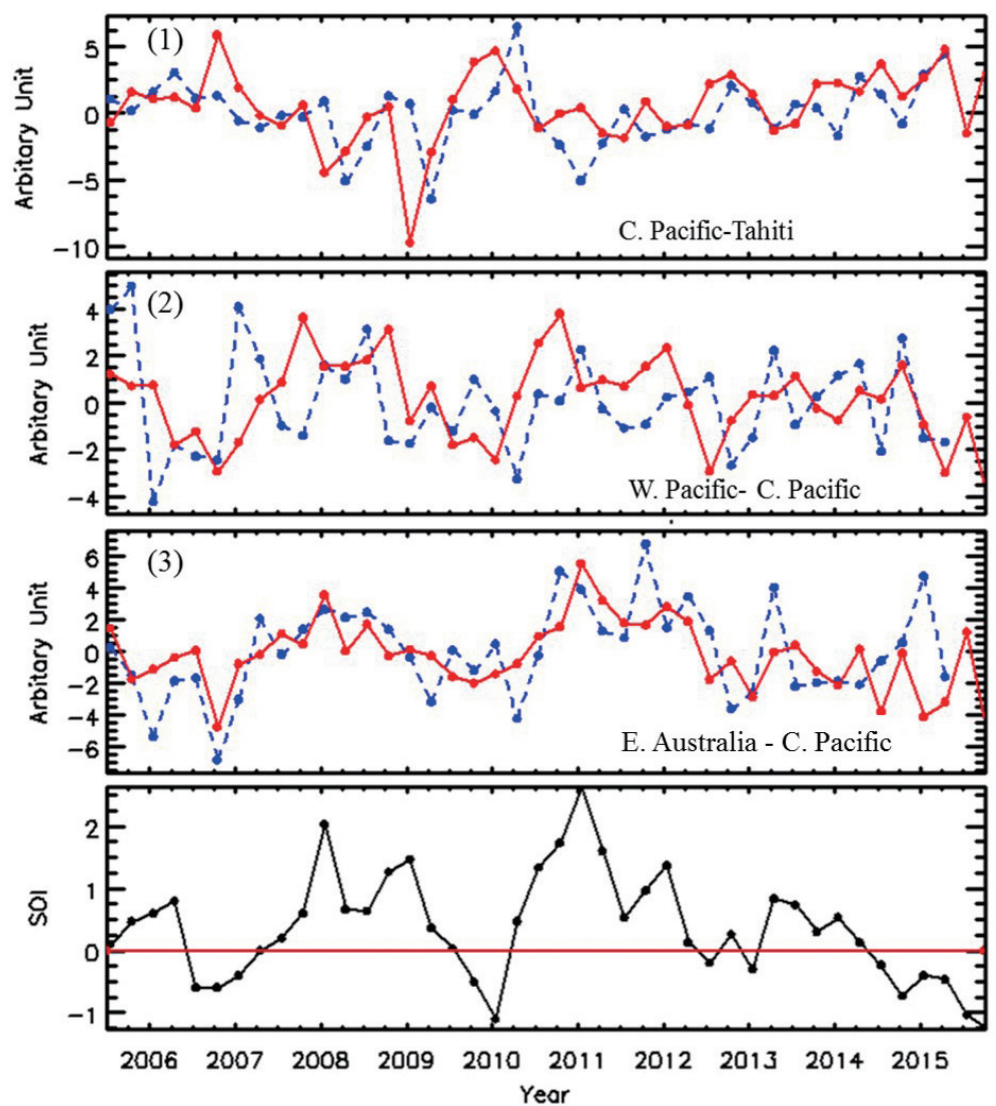

Fig. 5. The EAI and LAI in three pair areas over the Pacific Ocean. The red line denotes ISUAL elves and the blue line represents LIS lightning. The numbers in parentheses mark the pairs listed in Table 3. The bottom panel shows the Southern Oscillation Index (SOI). (Color online only) 
and Pair (3) east Australia - central Pacific, where Pairs (1) and (2) are found in the responsive regions reported in $\mathrm{Wu}$ et al. (2012). The range of each region is listed in Table 2. In the correlation coefficient comparisons (CC) with the SOI before and after the data record extension to SON 2015, the $\mathrm{CC}$ for each pair with the SOI is listed in Table 3. The strong SOI correlation between both lightning and elves remains with CC $\sim 0.6$ for both Pairs (1) and (2). The most responsive pair over the 10-year time frame is Pair (3), with values of 0.71 and 0.4 for elves and lightning, respectively. This result is expected as both C. Pacific and E. Australia are located in the SSTA-Horseshoe and SSTA-Pacific which are directly influenced by ENSO (Wang and Picaut 2004).

\section{ENSO-SENSITIVE REGIONS FOR ELVES IN THE INDIAN OCEAN}

The widespread influence of ENSO has been documented in many studies. The SST variation in the central and eastern Pacific modify the SST in the Indian Ocean via the so-called "Tropical Atmospheric Bridge" (Klein et al. 1999; Alexander et al. 2002; Lau and Nath 2003). Figure 4 shows that the SSTA in the Indian Ocean varies in phase with that in the central Pacific, that is to say, warmer in El Niño and colder in La Niña. Following the same analysis in section 4, the SSTA-Indian Ocean is defined by the area with SSTA over 90\% confidence interval. The enhanced AEOD and ALFD area percentages are listed in Table 1, with both elves and lightning enhanced in most areas in the SSTA-Indian Ocean in the warm phase, and remaining calm in the cold phase. Furthermore, the larger difference between the reduced and enhanced area is found in AEOD in the warm phase, where $22.9 \%$ of the area showed enhanced AEOD and $11.8 \%$ of the area showed reduced AEOD. In the meantime, ALFD reacts in an opposite way, with enhanced values over $18 \%$ of the SSTA-Indian Ocean and reduced values over $14.7 \%$ of the area. Similar to the result in SSTA-Horseshoe and SSTA-Pacific, elves in SSTA-Indian Ocean support the idea that elves do better than lightning in their responsiveness to ENSO.

To evaluate the ENSO influence in the Indian Ocean from the Pacific Ocean, east Australia is chosen as the reference area in the Pacific Ocean. The correlation analyses in the east (I1 in Fig. 3), central (I2 in Fig. 3), and west Indian Ocean (I3 in Fig. 3) with east Australia (C1 in Fig. 3) are given in Fig. 6 and Table 3. Three pairs of areas in the Indian Ocean are: Pair (4) the East Indian Ocean - east Australia, Pair (5) the central Indian Ocean - east Australia, and Pair (6) the west Indian Ocean - eastern Australia. Only moderate correlations are evident in the Indian Ocean as the correlation for no pair exceeds 0.5. However, EAI and LAI in Pair (5) C. Indian Ocean and Pair (6) W. Indian Ocean shows a significant trend varying with SOI during the period between El Niño and the following La Niña. The phase transition period in 2007 - 2008 and 2010 - 2011 are marked in
Fig. 6. Comparing the variation in SOI during the transition phase of El Niño and the following La Niña with the neutral condition, the increase in SOI per year is relatively larger. The persisting SST increase in the SSTA-Horseshoe region establishes a suitable environment for elves and lightning, so that EAI and LAI decrease while SOI increases. This phenomena is particularly significant in Pair (6) because the upwelling synoptic convection occurring in the east Indian Ocean near $60^{\circ} \mathrm{E}$ is coupled to the conjugate subsidence of the Walker Circulation over the west Pacific Ocean during El Niño and in the opposite sense during La Niña (Klein et al. 1999; Misra 2004).

\section{DISCUSSION}

As we discussed in sections 4 and 5 , it is clear that the occurrence of elves follows the upwelling of the synoptic circulation in specific features known as ITCZ, SPCZ, and Walker circulation. However, Sátori et al. (2009) suggested that more lightning occurs at the subsidence region of the synoptic circulation. The descending air suppresses the cloudiness and allows the solar radiation to heat the Earth's surface directly. The rising temperature at the surface is the basic mechanism to increase the convective available potential energy (CAPE), represented by the area on an epigram bounded by the wet bulb adiabatic and the environmental

Table 2. Longitude and latitude range of ENSO-sensitive regions where $\mathrm{C}, \mathrm{E}, \mathrm{W}$ are the abbreviations for Central, East, and West, respectively.

\begin{tabular}{cccc}
\hline Region code & Region name & Latitude & Longitude \\
\hline P1 & W. Pacific & $10^{\circ} \mathrm{S}-20^{\circ} \mathrm{N}$ & $130^{\circ} \mathrm{E}-150^{\circ} \mathrm{E}$ \\
P2 & C. Pacific & $10^{\circ} \mathrm{S}-10^{\circ} \mathrm{N}$ & $165^{\circ} \mathrm{E}-165^{\circ} \mathrm{W}$ \\
P3 & Tahiti & $25^{\circ} \mathrm{S}-5^{\circ} \mathrm{S}$ & $165^{\circ} \mathrm{W}-135^{\circ} \mathrm{W}$ \\
C1 & E. Australia & $25^{\circ} \mathrm{S}-5^{\circ} \mathrm{S}$ & $140^{\circ} \mathrm{E}-160^{\circ} \mathrm{E}$ \\
I1 & E. Indian Ocean & $25^{\circ} \mathrm{S}-5^{\circ} \mathrm{S}$ & $90^{\circ} \mathrm{E}-110^{\circ} \mathrm{E}$ \\
I2 & C. Indian Ocean & $25^{\circ} \mathrm{S}-5^{\circ} \mathrm{S}$ & $70^{\circ} \mathrm{E}-90^{\circ} \mathrm{E}$ \\
I3 & W. Indian Ocean & $25^{\circ} \mathrm{S}-5^{\circ} \mathrm{S}$ & $50^{\circ} \mathrm{E}-70^{\circ} \mathrm{E}$ \\
\hline
\end{tabular}

Table 3. The correlation coefficients (CC) of the sensitive pairs and SOI for EAI and LAI. The numbers in the parentheses are the results in Wu et al. (2012).

\begin{tabular}{lcc}
\hline \multicolumn{1}{c}{$\mathbf{N}=\mathbf{4 2}, \mathbf{P}<\mathbf{0 . 0 0 1}$} & Elves & Lightning \\
\hline (1) C. Pacific - Tahiti & $-0.53(-0.68)$ & $-0.37(-0.63)$ \\
(2) W. Pacific - C. Pacific & $0.63(0.63)$ & $0.08(0.36)$ \\
(3) C. Pacific - E. Australia & 0.71 & \\
(4) E. Indian Ocean - E. Australia & -0.23 & -0.42 \\
(5) C. Indian Ocean - E. Australia & -0.36 & -0.47 \\
(6) W. Indian Ocean - E. Australia & -0.45 & -0.22 \\
\hline
\end{tabular}




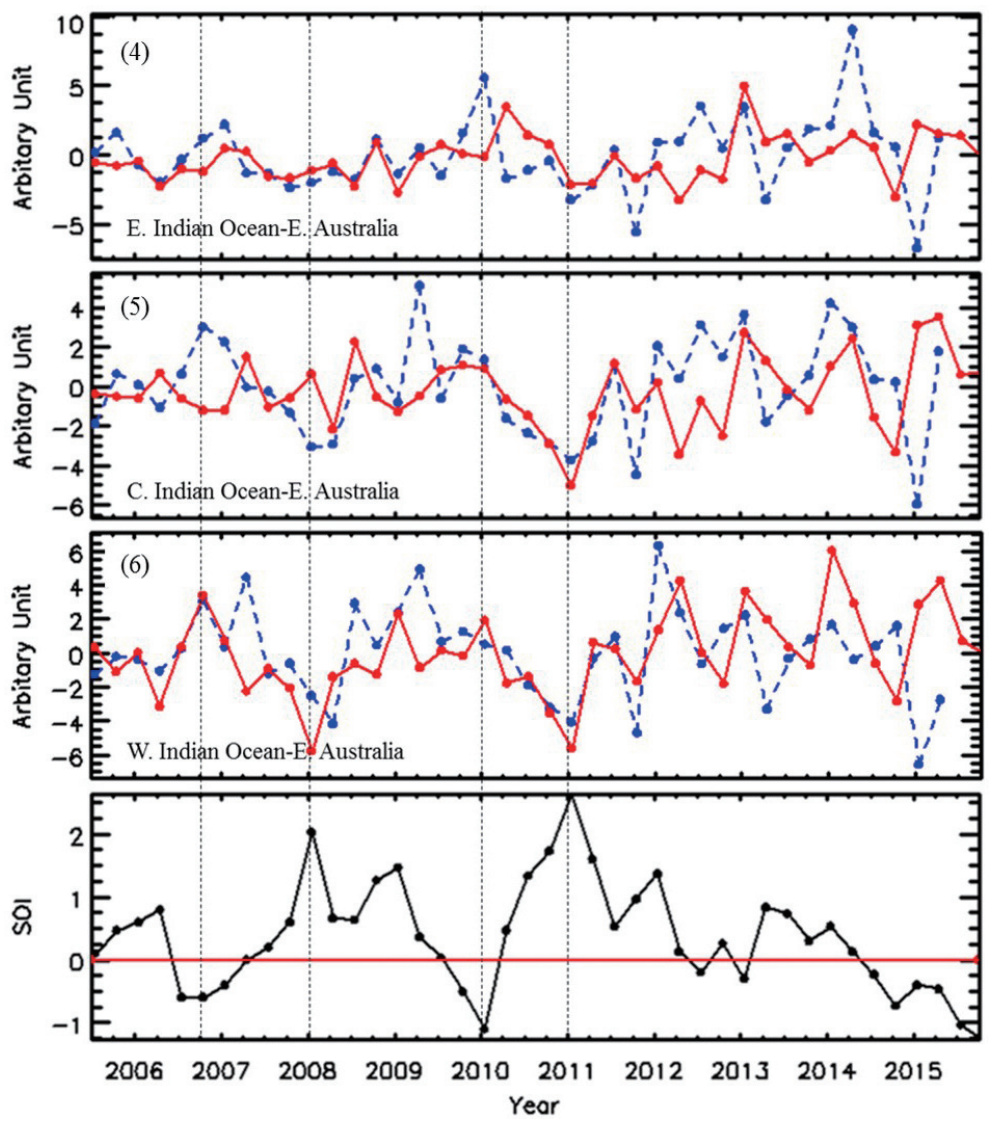

Fig. 6. The EAI and LAI in three pair areas over the Indian Ocean. The notations are the same as Fig. 5. The dashed lines mark the seasons for two El Niño events and the following strong La Niña events. (Color online only)

temperature profile (Williams and Renno 1993). The larger CAPE is associated with a larger maximum updraft speed (w) following the relationship $\mathrm{w} \propto C A P E^{1 / 2}$, with the lightning flash rate nonlinearly and positively dependent on $\mathrm{w}$ (Williams 1985; Price and Rind 1992; Baker et al. 1995; Yoshida et al. 2009). The most prominent difference between oceanic elve-producing lightning and general lightning is that larger peak currents are repeatedly observed in oceanic lightning and in the superlative lightning causal to elves (Barrington-Leigh et al. 2001; Hutchins et al. 2013; Said et al. 2013; Chen et al. 2014). Unlike general lightning, the thundercloud is expected to have a lower flash rate to build sufficient electric potential for large peakcurrent breakdown (Chronis et al. 2015). Therefore, the parent thundercloud for elves would have weaker vertical updraft than the general lightning. The active overturning in the oceanic troposphere prevents the large CAPE in the upwelling region (Williams et al. 2002), which the CAPE value is around 1000 joule $\mathrm{kg}^{-1}$ or less while greater CAPE (1000 - 3000 joule $\mathrm{kg}^{-1}$ ) can be achieved for storms removed from the ITCZ (Williams 2003). The weaker CAPE in the upwelling region of the synoptic circulation provides an environment favorable to the development of elve-producing thunderstorms, such that the elve lightning shows better agreement than ordinary lightning with the variation in the synoptic circulation and ENSO.

\section{CONCLUSIONS}

The elve occurrence during El Niño and La Niña was studied in Wu et al. (2012) with 5 years of ISUAL satellite observations. Given the historical El Niño in the period 2015 - 2016 and now receiving wide attention, it is timely to revisit this issue with a 10 -year data set. Three regions with significant SSTA in ENSO episodes are discussed, the percentage of area with enhanced AEOD follows the change in SSTA in SSTA-Horseshoe, SSTA-Pacific, and SSTA-Indian Ocean, whereas the variation in ALFR with ENSO phase is rather ambiguous. Compared with the results in $\mathrm{Wu}$ et al. (2012), the correlation of the predominant pairs remains close to 0.6, while the most ENSO-responsive region over the 10-year time frame is found to be the east Australia-central Pacific pair where the correlation coefficient with SOI is 0.71. In addition to the Pacific region, the EAI and LAI are also tested in the Indian Ocean. The elve response is stronger in the west Indian Ocean where the synoptic circulation is affected, particularly during the period between a strong El Niño and the following strong La Niña. From the result 
above, the weaker CAPE in the upwelling region of the synoptic circulation provides the environment to develop elveproducing thunderstorms, such that the elves have better agreement than lightning with the variation in the synoptic circulation and ENSO. This work substantiates the findings in Wu et al. (2012), now with data in a longer10-year time frame, that elves are more sensitive than lightning to ENSO and the variation in the synoptic circulation. Accordingly, the continuous monitoring of elves deserves consideration for future satellite missions.

Acknowledgements The authors would like to thank Earle Williams for the valuable discussion. We also thank to Sung-Ming Huang and Li-Jou Lee for both scientific ideas and data processing support. Last but not least, the first author thanks Chao-Min Chen for insights from the meteorological point of view. The sea surface temperature data from NOAA/OAR/ESRL PSD and the lightning data from LIS/ TRMM provided by the NASA Global Hydrology Resource Center DAAC are most appreciated. This work was supported in part by the Ministry of Science and Technology in Taiwan under grant MOST 104-2111-M-006 -005-MY2.

\section{REFERENCES}

Alexander, M. A., I. Bladé, M. Newman, J. R. Lanzante, N. C. Lau, and J. D. Scott, 2002: The Atmospheric Bridge: The Influence of ENSO teleconnections on air-sea interaction over the global oceans. J. Climate, 15, 2205-2231, doi: 10.1175/1520-0442(2002)015<22 05:TABTIO > 2.0.CO;2. [Link]

Ashok, K., S. K. Behera, S. A. Rao, H. Weng, and T. Yamagata, 2007: El Niño Modoki and its possible teleconnection. J. Geophys. Res., 112, C11007, doi: 10.1029/2006JC003798. [Link]

Baker, M. B., H. J. Christian, and J. Latham, 1995: A computational study of the relationships linking lightning frequency and other thundercloud parameters. Q.J. R. Meteorol. Soc., 121, 1525-1548, doi: 10.1256/smsqj.52702. [Link]

Barrington-Leigh, C. P., U. S. Inan, and M. Stanley, 2001: Identification of sprites and elves with intensified video and broadband array photometry. J. Geophys. Res., 106, 1741- 1750, doi: 10.1029/2000JA000073. [Link]

Boccippio, D. J., S. J. Goodman, and S. Heckman, 2000: Regional differences in tropical lightning distributions. J. Appl. Meteorol., 39, 2231-2248, doi: 10.1175/15200450(2001)040<2231:RDITLD>2.0.CO;2. [Link]

Camberlin, P., S. Janicot, and I. Poccard, 2001: Seasonality and atmospheric dynamics of the teleconnection between African rainfall and tropical sea-surface temperature: Atlantic vs. ENSO. Int. J. Climatol., 21, 9731005, doi: 10.1002/joc.673. [Link]

Chang, S. C., C. L. Kuo, L. J. Lee, A. B. Chen, H. T. Su, R.
R. Hsu, H. U. Frey, S. B. Mende, Y. Takahashi, and L. C. Lee, 2010: ISUAL far-ultraviolet events, elves, and lightning current. J. Geophys. Res., 115, A00E46, doi: 10.1029/2009JA014861. [Link]

Chang, S. C., R. R. Hsu, S. M. Huang, H. T. Su, C. L. Kuo, J. K. Chou, L. J. Lee, Y. J. Wu, and A. B. Chen, 2014: Characteristics of TLE-producing lightning in a coastal thunderstorm. J. Geophys. Res., 119, 9303-9320, doi: 10.1002/2014JA019819. [Link]

Chen, A. B., C. L. Kuo, Y. J. Lee, H. T. Su, R. R. Hsu, J. L. Chern, H. U. Frey, S. B. Mende, Y. Takahashi, H. Fukunishi, Y. S. Chang, T. Y. Liu, and L. C. Lee, 2008: Global distributions and occurrence rates of transient luminous events. J. Geophys. Res., 113, A08306, doi: 10.1029/2008JA013101. [Link]

Chen, A. B., Y. J. Wu, C. Y. Chiang, Y. C. Huang, C. L. Kuo, H. T. Su, R. R. Hsu, S. B. Mende, H. U. Frey, S. E. Harris, Y. Takahashi, and L. C. Lee, 2012: Sensitivity degradation of ISUAL instruments and its impact on observations. Terr. Atmos. Ocean. Sci., 23, 71-83, doi: 10.3319/TAO.2011.06.20.01(AA). [Link]

Chen, A. B. C., H. T. Su, and R. R. Hsu, 2014: Energetics and geographic distribution of elve-producing discharges. J. Geophys. Res., 119, 1381-1391, doi: 10.1002/2013JA019470. [Link]

Chern, J. L., R. R. Hsu, H. T. Su, S. B. Mende, H. Fukunishi, Y. Takahashi, and L. C. Lee, 2003: Global survey of upper atmospheric transient luminous events on the ROCSAT-2 satellite. J.Atmos. Sol.-Terr. Phys., 65, 647-659, doi: 10.1016/S1364-6826(02)00317-6. [Link]

Christian, H. J., R. J. Blakeslee, S. J. Goodman, D. A. Mach, M. F. Stewart, D. E. Buechler, W. J. Koshak, J. M. Hall, W. L. Boeck, K. T. Driscoll, and D. J. Boccippio, 1999: The Lightning Imaging Sensor. Proceedings of the 11th International Conference on Atmospheric Electricity, Guntersville, Alabama, June 7-11, 746-749.

Christian, H. J., R. J. Blakeslee, D. J. Boccippio, W. L. Boeck, D. E. Buechler, K. T. Driscoll, S. J. Goodman, J. M. Hall, W. J. Koshak, D. M. Mach, and M. F. Stewart, 2003: Global frequency and distribution of lightning as observed from space by the Optical Transient Detector. J. Geophys. Res., 108, 4005, doi: 10.1029/2002JD002347. [Link]

Chronis, T. G., S. J. Goodman, D. Cecil, D. Buechler, F. J. Robertson, J.Pittman, and R. J. Blakeslee, 2008: Global lightning activity from the ENSO perspective. J. Geophys. Res., 35, L19804, doi: 10.1029/2008GL034321. [Link]

Chronis, T., K. Cummins, R. Said, W. Koshak, E. McCaul, E. R. Williams, G. T. Stano, and M. Grant, 2015: Climatological diurnal variation of negative CG lightning peak current over the continental United States. J. Geophys. Res., 120, 582-589, doi: 10.1002/2014JD022547. [Link] 
Dowdy, A. J., 2016: Seasonal forecasting of lightning and thunderstorm activity in tropical and temperate regions of the world. Scientific Reports 6, Article number: 20874, doi: 10.1038/srep20874. [Link]

Franz, R. C., R. J. Nemzek, and J. R. Winckler, 1990: Television image of a large upward electrical discharge above a thunderstorm system. Science, 249, 48-51, doi: 10.1126/science. 249.4964.48. [Link]

Friedrich, M. and K. M. Torkar, 1992: An empirical model of the non-auroral D Region. Radio Sci., 27, 945-953, doi: 10.1029/92RS01929. [Link]

Fukunishi, H., Y. Takahashi, M. Kubota, K. Sakanoi, U. S. Inan, and W. A. Lyons, 1996: Elves: Lightninginduced transient luminous events in the lower ionosphere. Geophys. Res. Lett., 23, 2157-2160, doi: 10.1029/96GL01979. [Link]

Haffke, C. and G. Magnusdottir, 2013: The South Pacific Convergence Zone in three decades of satellite images. J. Geophys. Res., 118, 10839-10849, doi: 10.1002/ jgrd.50838. [Link]

Hutchins, M. L., R. H. Holzworth, K. S. Virts, J. M. Wallace, and S. Heckman, 2013: Radiated VLF energy differences of land and oceanic lightning. Geophys. Res. Lett., 40, 2390-2394, doi: 10.1002/grl.50406. [Link]

Inan, U. S., W. A. Sampson, and Y. N. Taranenko, 1996: Space-time structure of optical flashes and ionization changes produced by lighting-EMP. Geophys. Res. Lett., 23, 133-136, doi: 10.1029/95GL03816. [Link]

Klein, S. A., B. J. Soden, and N. Lau, 1999: Remote sea surface temperature variations during ENSO: Evidence for a tropical atmospheric bridge. J. Climate, 12, 917932, doi: 10.1175/1520-0442(1999)012<0917:RSSTV $\mathrm{D}>2.0 . \mathrm{CO} ; 2$. [Link]

Kuo, C. L., A. B. Chen, Y. J. Lee, L. Y. Tsai, R. K. Chou, R. R. Hsu, H. T. Su, L. C. Lee, S. A. Cummer, H. U. Frey, S. B. Mende, Y. Takahashi, and H. Fukunishi, 2007: Modeling elves observed by FORMOSAT-2 satellite. J. Geophys. Res., 112, doi: 10.1029/2007JA012407. [Link]

Lau, N. and M. J. Nath, 2003: Atmosphere-Ocean Variations in the Indo-Pacific Sector during ENSO Episodes. J. Climate, 16, 3-20, doi: 10.1175/1520-0442(2003)01 6<0003:AOVITI $>2.0 . \mathrm{CO} ; 2$. [Link]

Lee, L. J., A. B. Chen, S. C. Chang, C. L. Kuo, H. T. Su, R. R. Hsu, C. C. Wu, P. H. Lin, H. U. Frey, S. B. Mende, Y. Takahashi, and L. C. Lee, 2010: Controlling synoptic-scale factors for the distribution of transient luminous events. J. Geophys. Res., 115, A00E54, doi: 10.1029/2009JA014823. [Link]

Lyons, W. A., 1994: Characteristics of luminous structures in the stratosphere above thunderstorms as imaged by low-light video. Geophys. Res. Lett., 21, 875-878, doi: 10.1029/94GL00560. [Link]

Marshall, R. A. and U. S. Inan, 2010: Two-dimensional fre- quency domain modeling of lightning EMP-induced perturbations to VLF transmitter signals. J. Geophys. Res., 115, A00E29, doi: 10.1029/2009JA014761. [Link]

Mende, S. B., H. U. Frey, R. R. Hsu, H. T. Su, A. B. Chen, L. C. Lee, D. D. Sentman, Y. Takahashi, and H. Fukunishi, 2005: D region ionization by lightning-induced electromagnetic pulses. J. Geophys. Res., 110, A11312, doi: 10.1029/2005JA011064. [Link]

Misra, V., 2004: The teleconnection between the Western Indian and the Western Pacific Oceans. Mon. Weather Rev., 132, 445-455, doi: 10.1175/1520-0493(2004)132 $<0445$ :TTBTWI $>2.0 . \mathrm{CO} ; 2$. [Link]

Nag, A., M. J. Murphy, K. L. Cummins, A. E. Pifer, and J. A. Cramer, 2014: Recent evolution of the U.S. National Lightning Detection Network. In: Proc. 23rd International Lightning Detection Conference \& 5th International Lightning Meteorology Conference, ISBN 978-0-9894826-1-5, Tucson, Arizona, doi: 10.13140/2.1.4443.1047. [Link]

Ortega, P., A. Guha, E. Williams, and G. Satori, 2014: Schumann resonance observations from the Central Pacific Ocean. XV International Conference on Atmospheric Electricity, 15-20 June 2014, Norman, Oklahoma, U.S.A.

Pasko, V. P., 2010: Recent advances in theory of transient luminous events. J. Geophys. Res., 115, A00E35, doi: 10.1029/2009JA014860. [Link]

Price, C., 2009: Thunderstorms, lightning and climate change. In: Betz, H. D., U. Schumann, and P. Laroche (Eds.), Lightning: Principles, Instruments and Applications, Springer Netherlands, doi: 10.1007/978-1-40209079-0_24. [Link]

Price, C. and D. Rind, 1992: A simple lightning parameterization for calculating global lightning distributions. J. Geophys. Res., 97, 9919-9933, doi: 10.1029/92JD00719. [Link]

Reynolds, R. W., N. A. Rayner, T. M. Smith, D. C. Stokes, and W. Wang, 2002: An improved in situ and satellite SST analysis for climate. J. Climate, 15, 1609-1625, doi: 10.1175/1520-0442(2002)015<1609:AIISAS>2.0 .CO;2. [Link]

Said, R. K., M. B. Cohen, and U. S. Inan, 2013: Highly intense lightning over the oceans: Estimated peak currents from global GLD360 observations. J. Geophys. Res., 118, 6905-6915, doi: 10.1002/jgrd.50508. [Link]

Sátori, G., E. Williams, and I. Lemperger, 2009: Variability of global lightning activity on the ENSO time scale. Atmos. Res., 91, 500-507, doi: 10.1016/j.atmosres.2008.06.014. [Link]

Sentman, D. D. and E. M. Wescott, 1993: Observations of upper atmospheric optical flashes recorded from an aircraft. Geophys. Res. Lett., 20, 2857-2860, doi: 10.1029/93GL02998. [Link]

Su, H. T., R. R. Hsu, A. B. Chen, Y. C. Wang, W. S. Hsiao, 
W. C. Lai, L. C. Lee, M. Sato, and H. Fukunishi, 2003: Gigantic jets between a thundercloud and the ionosphere. Nature, 423, 974-976, doi: 10.1038/nature01759. [Link]

Trenberth, K. E., 1997: The definition of El Niño. Bull. Amer. Meteorol.Soc., 78, 2771-2777, doi: 10.1175/15 20-0477(1997)078<2771:TDOENO>2.0.CO;2. [Link]

Walker, G. T., 1923: Correlation in seasonal variations of weather, VIII: A preliminary study of world weather. Memoirs of the India Meteorological Department, 24, 75-131.

Wang, B., R. Wu, and X. Fu, 2000: Pacific-East Asian teleconnection: How does ENSO affect East Asian Climate? J. Climate, 13, 1517-1536, doi: 10.1175/1520-0 442(2000)013<1517:PEATHD>2.0.CO;2. [Link]

Wang, C. and J. Picaut, 2004: Understanding ENSO physics - A review. In: Wang, C., S. P. Xie, and J. A. Carton (Eds.), Earth's Climate: The Ocean-Atmosphere Interaction, Geophysical Monograph Series, Volume 147, AGU, Washington, D.C., 21-48, doi: 10.1029/147GM02. [Link]

Wang, C., C. Deser, J. Yu, P. DiNezio, and A. Clement, 2016: El Niño and Southern Oscillation (ENSO): A review. In: Glynn, P. W., D. P. Manzello, and I. C. Enochs (Eds.), Coral Reefs of the Eastern Tropical Pacific, Springer, Berlin, 85-106, doi: 10.1007/978-94017-7499-4_4. [Link]

Westfall, P. H. and K. S. S. Henning, 2013: Understanding Advanced Statistical Methods, CRC Press, Boca Raton.

Williams, E. and N. Renno, 1993: An analysis of the conditional instability of the tropical atmosphere. Mon. Weather Rev., 121, 21-36, doi: 10.1175/1520-0493(19 93) $121<0021$ :AAOTCI>2.0.CO;2. [Link]

Williams, E., D. Rosenfeld, N. Madden, J. Gerlach, N. Gears, L. Atkinson, N. Dunnemann, G. Frostrom, M. Antonio, B. Biazon, R. Camargo, H. Franca, A. Gomes, M. Lima, R. Machado, S. Manhaes, L. Nachtigall, H. Piva, W. Quintiliano, L. Machado, P. Artaxo, G. Roberts, N. Renno, R. Blakeslee, J. Bailey, D. Boccippio, A. Betts, D. Wolff, B. Roy, J. Halverson, T. Rickenbach, J. Fuentes, and E. Avelino, 2002: Contrasting convective regimes over the Amazon: Implications for cloud electrification. J. Geophys. Res., 107, doi: 10.1029/2001JD000380. [Link]
Williams, E. R., 1985: Large-scale charge separation in thunderclouds. J. Geophys. Res., 90, 6013-6025, doi: 10.1029/JD090iD04p06013. [Link]

Williams, E. R., 1992: The Schumann resonance: A global tropical thermometer. Science, 256, 1184-1187, doi: 10.1126/science.256.5060.1184. [Link]

Williams, E. R., 2003: Charge structure and geographical variation of thunderclouds. In: Cooray, V. (Ed.), The Lightning Flash, The Institution of Engineering and Technology, London, United Kingdom, 1-16, doi: 10.1049/PBPO034E_ch1. [Link]

Williams, E. R., 2005: Lightning and climate: A review. Atmos. Res., 76, 272-287, doi: 10.1016/j.atmosres.2004.11.014. [Link]

Williams, E. R., 2012: Franklin Lecture: Lightning and Climate, American Geophysical Union, Fall Meeting, December 2012.

Williams, E. R., 2013: Global connections: A selection of long unsolved problems (Invited), American Geophysical Union, Fall Meeting 2013, abstract \#AE22A-05.

Wu, Y. J., A. B. Chen, H. H. Hsu, J. K. Chou, S. C. Chang, L. J. Lee, Y. J. Lee, H. T. Su, C. L. Kuo, R. R. Hsu, H. U. Frey, S. B. Mende, Y. Takahashi, and L. C. Lee, 2012: Occurrence of elves and lightning during El Niño and La Niña. Geophys. Res. Lett., 39, L03106, doi: 10.1029/2011GL049831. [Link]

Wu, Y. J., E. Williams, S. C. Chang, J. K. Chou, R. R. Hsu, M. Friedrich, C. L. Kuo, A. B. Chen, K. M. Peng, H. T. Su, H. U. Frey, S. B. Mende, Y. Takahashi, and L. C. Lee, 2017: The leading role of atomic oxygen in the collocation of elves and hydroxyl nightglow in the low-latitude mesosphere. J. Geophys. Res., 122, 55505567, doi: 10.1002/2016ja023681. [Link]

Wyrtki, K., 1975: Investigation of the EI Nino phenomenon in the Pacific Ocean. Environmental Conservation, 2, 281-282, doi: 10.1017/S0376892900001806. [Link]

Yeh, S., J. Kug, B. Dewitte, M. Kwon, B. P. Kirtman, and F. Jin, 2009: El Nino in a changing climate. Nature, 461, 511-514, doi: 10.1038/nature08316. [Link]

Yoshida, S., T. Morimoto, T. Ushio, and Z. Kawasaki, 2009: A fifth-power relationship for lightning activity from Tropical Rainfall Measuring Mission satellite observations. J. Geophys. Res., 114, D09104, doi: 10.1029/2008JD010370. [Link] 